\title{
AN INVESTIGATION INTO THE FEASIBLITY OF TASMANIAN STONEFRUIT GROWERS EMPLOYING ELECTRONIC COMMERCE
}

\author{
Stewart Pedersen \\ School of Information Systems \\ Faculty of Commerce and Law \\ University of Tasmania \\ Hobart, Australia \\ Email: Stewart.Pedersen@infosys.utas.edu.au
}

\begin{abstract}
This research presents an assessment of the feasibility of Tasmanian stonefruit growers adopting electronic commerce. In order to achieve this aim, a number of qualitative techniques were employed under an action research methodology. Although not all applications of electronic commerce are suitable within the environment under study, it is suggested that there are ways in which electronic commerce could provide value. However, inhibitors, some common to Small to Medium Sized Enterprises (SMEs), do exist. There is a need for these issues to be understood prior to adopting electronic commerce.
\end{abstract}

\section{KEYWORDS}

Hb03 agribusiness is, ai0101 action research, da0201 small business

\section{INTRODUCTION}

It is well documented that many organisations are realising benefits from the utilisation of electronic commerce. For example, some are employing EDI and JT to manage their supply chains (Mackay 1996; Schware \& Kimberley 1995b; McCarthy et al. 1997). Others are harnessing the Internet to distribute product information, reach niché markets and so forth (Plunkett 1997; McCarthy et al. 1997; Kalakota \& Whinston 1996). However, not all electronic commerce applications are suitable in all circumstances. Selling products via the Internet is one such case.

\section{Internet Sales}

Gregor et al. (1997:599) argue that "Other things being equal, the suitability of products for the direct market of the World Wide Web increases with (i) lower levels of asset specificity, (ii) higher levels of information intensity and, (iii) higher levels of adequacy of description".

Further, Gregor et al. (1997:592) state that "Many agricultural products have asset specificity in that they are time specific- they need to be marketed, or reach a consumer, within a specified, relatively limited time period". The authors note that the agricultural products being sold directly to customers via the Internet, such as bull semen and farm supplies, have low asset specificity. They can be stored suitably for an extended period of time.

Information intensity refers to the amount of information required to describe a product. The more information required, the higher the information intensity. Adequacy of description refers to the degree to which the product can be satisfactorily described. Products such as bull semen are more suitable for Internet sales because actually viewing the product would not reveal more information (Gregor et al. 1997). However, this may not be the case for other agricultural commodities, particularly those bought fresh for consumption.

\section{Disintermediation}

The sale of products directly over the Internet can involve the bypassing of entities commonly found in a supply chain, such as wholesalers and retailers. EDI can also support this. Indeed, one of strengths of electronic commerce is that it allows for the removal of those intermediaries who are not adding value ${ }^{6}$. Industries where this has occurred include airlines (Noe et al. 1997; Row 1996) and publishers (Golden 1996).

${ }^{6}$ Blanchard, P., (4/8/97) Personal Conversation, Tradegate ECA. 


\section{Intermediaries in Agriculture}

However, it is possible to argue for the necessity of intermediaries for some agricultural products. Intermediaries perform a variety of functions for those above and below them in the supply chain. For example, amongst other things, wholesalers assist suppliers (generally producers or importers) by providing market information. They also assist customers (in this case, retailers) by providing prompt, low cost delivery (McCarthy et al. 1997).

Matsuda (1994) notes the importance of the role of wholesalers in the agricultural industry. This role derives from the nature of the industry. From the point of view of supply, there are large numbers of small, geographically dispersed growers, and from the point of view of demand, there are also great numbers of dispersed consumers. The wholesale markets act to bridge the gap between growers and consumers. Kinsey (1994) suggests changes in consumer attitudes regarding food consumption have resulted in a move towards small, diverse and customised niché markets, forcing retailers to handle broader lines of commodities more efficiently. As a corollary, retailers prefer to purchase the commodities they intend to sell at a market where all the commodities they require are assembled.

Further, Matsuda et al. (1997) state that wholesale markets are more efficient and effective at finding an accurate market price. Neither the farmers, who do not individually produce sufficient volumes, nor the consumers, who purchase only small amounts of produce, can influence the market price. Both are considered price takers (Matsuda 1996). Intermediaries, in the form of wholesalers, perform an important pricing function, and add value. These factors have contributed to the need for intermediary institutions to coordinate transactions in relation to supply and demand. McCarthy et al. (1997:412) hold that "Eliminating wholesalers would not eliminate the need for the functions they provide, and it would be wrong to assume that direct channels would necessarily be more efficient".

\section{Value in Agriculture}

Electronic commerce can add value in agricultural endeavours. Gregor et al. (1997) use Porter's five-forces model to illustrate. Porter (1990) offers the following as factors that shape an industry:

- Bargaining power of suppliers;

- Bargaining power of buyers;

- Threat of substitute products or services;

- Rivalry among existing competitors; and,

- Threat of new entrants.

The following is a summary provided by Gregor et al. (1997:592) of three generic strategies to counter these forces, and the manner in which they can be supported by electronic commerce:

- Cost leadership, which can be achieved through cheaper product promotion, i.e. via the Internet;

- Product differentiation, which can be achieved by cost leadership and improved customer service and delivery; and,

- Innovation in business methods, which can be achieved by improved methods of production, marketing and distribution. For example, increasing potential marketing exposure via the Internet.

\section{Infrastructure}

Given that electronic commerce can provide value in agricultural endeavours, it is important to note that any attempt to employ electronic commerce within a given industry requires an assessment of the technical infrastructure (Bloch et al. 1996). Authors such as Kalakota and Whinston (1996) and Schware and Kimberley (1995a, 1995b) indicate that the benefits of electronic commerce are reliant upon other trading partners employing electronic commerce. Even if a specific industry has the hardware and software requirements, having the ability to use electronic commerce is of little use if other necessary entities in the value or supply chain are unable to participate.

\section{Change}

As the uptake of electronic commerce essentially involves change, attention must be paid to the organisational as well as technical infrastructure. Bloch et al. (1996:110) state that "...building any kind of electronic commerce system requires a strategy, i.e. a vision of the goal to achieve...". Change management literature illustrates that past 
attempts to change are important to consider when planning new changes. Historical failures and successes can have positive and negative effects, and intrinsically have an impact on the culture within an organisation or industry. As noted by Burnes (1996) and Dawson (1996), if the proposed changes contradict the existing culture, implementation is considerably more difficult. Both the technical and organisational infrastructure must be taken into account when considering incorporating new methodologies within a given industry.

\section{RESEARCH OBJECTIVES AND QUESTION}

The utilisation of electronic commerce is permeating all industry sectors, including primary industry. Primary industry has traditionally been important to the Tasmanian economy. The growing of stonefruit has an established history within the state, and forecasts predict a rise in production. Given the increased use of electronic commerce globally, and an expanding stonefruit industry, it is necessary for Tasmanian stonefruit growers to have an understanding of how electronic commerce technologies may be applied within their business processes. Thus, the objectives of this research were as follows:

- To discover how electronic commerce could be employed by Tasmanian stonefruit growers; and,

- To empower the Tasmanian stonefruit growers with this knowledge and engender an understanding of the possible applications and limitations.

To address these objectives, the following research question was been formulated:

What potential is there for the utilisation of electronic commerce by Tasmanian stonefruit growers?

This investigation is important, not only in view of the increasing use of electronic commerce, but also because funding for agricultural research in Australia and most overseas countries has been scaled down over the last 10-15 years. Research into the areas of production, marketing and infrastructure must continue if our agricultural industries are to remain viable ${ }^{7}$.

\section{RESEARCH DESIGN AND METHODOLOGY}

Given that pursuit of the research question required the researcher's active participation in the environment under study, the subjective ontology associated with interpretivism was appropriate. Further, achievement of the research objectives requires the participation of growers themselves. Hence an action research methodology was adopted.

The concept of action research stems from the work of social psychologist Kurt Lewin (Burnes 1996). Lewin formulated a model consisting of a series of spiraling actions, with a distinct emphasis on group activity (Schermerhorn et al. 1988). The methodology associated with Lewin's model falls under the interpretivist approach (Acterberg et al. 1991).

Bailey et al. (1991:504) offer the following definition:

Action research is a process of systematically collecting data on an organisation, feeding it back to the members for action planning and evaluating results by collecting and reflecting on more data after the planned actions have been taken.

\section{Data Collection and Analysis}

In order to gain an understanding of the pertinent issues, data collection is a major part in the action research process (Schermerhorn et al. 1988). The methods utilised in the collection of data are situationally dependent; the researcher, or change agent, asks questions, conducts interviews, distributes questionnaires, makes field notes and listens to the concerns of those involved (Schermerhorn et al. 1988; Robbins 1994). However, in all cases these activities are carried out participatively (Burnes 1996).

In this research a variety of methods were used to collect data, including those mentioned above. The available literature was approached for instruction on the employment of the data collection techniques. Pilot studies were performed prior to the administration of a quantitative questionnaire, as the literature suggests (Minichiello et al. 1995). The questionnaire was administered to 60 of the 80 growers. The results formed a basis for further investigation. Data collected through field notes, personal conversations and interview transcripts were analysed using grounded theory to identify common themes (Strauss 1987).

${ }^{7}$ Brown, G., (26/09/97) Personal Conversation, Department of Primary Industry and Fisheries, Hobart, Tasmania. 


\section{Validity}

Validity is an important factor in qualitative research, as the researcher intrinsically applies their own norms and values when analysing the data. For this reason the researcher must verify the information with the participants to ensure the interpretations are accurate. Neuman (1994:357) states that "Member validity occurs when a researcher takes field results back to members, who judge their adequacy". Participants confirmed key research findings, and thus validity was achieved.

External validity is the ability to generalise experimental findings to events and settings outside the experiment itself (Neuman 1994:185). High external validity means the results can be generalised to many situations and many groups of people. Low external validity means that the results only apply to a very specific setting (Neuman 1994:135). The researcher has not attempted to generalise beyond the scope of the study. However, it is conceivable that the findings may be applicable to other, similar, situations.

\section{Relevant Utilisation}

It is appropriate to support the selection of a methodology by offering evidence of its successful utilisation in previous investigations within similar industries. Whyte (1991) reports that interest in participatory strategies for agricultural research became more widespread long after their application within other industries. Since its adoption however, action research has been used as a successful means for evoking and managing change in numerous agricultural research undertakings.

\section{Cyclical Approach}

Conducting the research as a participatory endeavour required that growers were aware of the research objectives and that a sufficient number of growers were willing to work towards those objectives. The identification of potential key agents of change was also necessary. Throughout the investigation the researcher remained in contact with the growers by telephone, conducted visits to their orchards and used Email where available. Grower's queries on the subject of electronic commerce were either answered immediately, or researched and the information provided at a later date.

Each time information was fed back, new issues arose, and the process continued. For example, many growers originally thought that electronic commerce was limited to the ability to sell their fruit directly over the Internet. Growers were informed that this was only one application of electronic commerce, and that there were many more. Some applications they were familiar with, such as EFTPOS, and some such as EDI were new to most growers.

Once this had been established, growers asked how they could use these technologies, and in particular, how they could sell their fruit over the Internet. This led to an investigation of the appropriateness of selling certain products via the Internet, and to the conclusion that stonefruit was not a product suited to such sales. Growers asked what they could use it for then, and the investigation revealed that the Internet could be used for such things as niché marketing of value added products. The process was one of learning for both the researcher and the growers. At all times growers were encouraged to discuss issues among themselves. It was emphasised that any decision to use electronic commerce technologies in a given fashion must be made by them. The researcher's role was that of consultant and facilitator.

\section{OVERVIEW OF THE TASMANIAN STONEFRUIT INDUSTRY}

A precise figure regarding the total number of stonefruit growers in Tasmania is difficult to acquire. The Department of Primary Industry and Fisheries considers plantings over one acre in size to be an orchard, while the Australian Bureau of Statistics only recognises holdings returning in excess of $\$ 22,500$ annually. However, in view of the nature of the industry in Tasmania, with all growers falling into the SME category and about half not using growing as a primary form of income, it was deemed more appropriate to consider the DPIF figures.

The DPIF recognises approximately 80 stonefruit orchards statewide. Of these, about 55 are cherry orchards, with apricots constituting most of the remainder. Cherries and apricots are popular with growers as Tasmania has a longer 
growing season than the mainland. The vast majority of orchards are family owned; there are only two corporate orchards. Most growers have just one stonefruit crop, but only a few grow stonefruit exclusively.

Of the 80 orchardists, half belong to the Tasmanian Stonefruit Growers' Association. These 40 produce around $80-$ $90 \%$ of the total stonefruit grown, and use their holdings as a primary source of income. The remaining 40 growers have other forms of employment and use stonefruit production as an income supplement. The average smaller grower produces from a holding of one or two hectares, which provides insufficient returns for sole reliance.

\section{Industry Trends}

In 1984 Tasmania produced 40 tonnes of cherries. Since 1987-88 there has been an increase in new orchards of about $10 \%$ annually according to the DPI, and this trend is expected to continue. Cherries have been the main focus of new orchards, and it is predicted that by the year 2000 Tasmania will have a production potential of about 1000 tonnes of cherries annually, not counting new plantings. Currently the production potential is around 600 tonnes, although in 1996 adverse environmental conditions resulted in a yield estimated at 200 tonnes.

\section{Flow of Goods and Information}

Growers are responsible for a myriad of activities ranging from soil preparation and crop production to grading and marketing their produce. These activities require the exchange of goods in the form of supplies and produce, and information, such as market prices. A graphical depiction of the flow of goods and information is provided in Figure 1 :

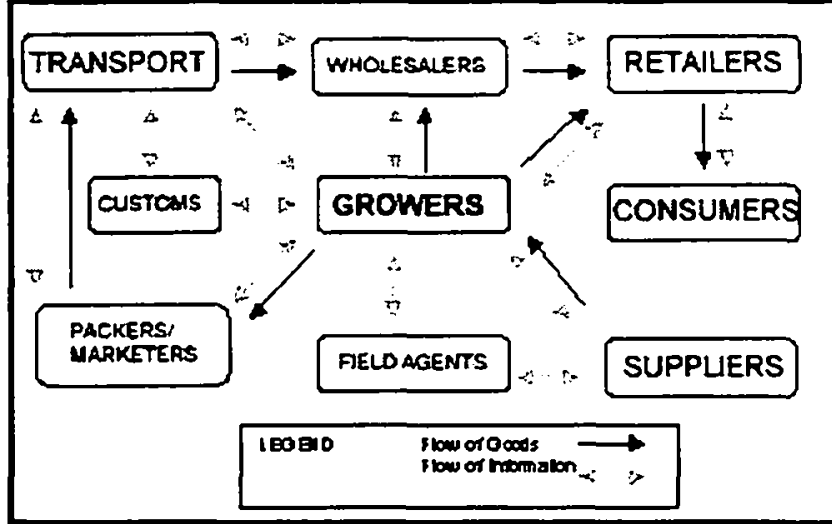

Figure 1. Flow of Goods and htormstion in the Tasmanian Stonefrut Industy

\section{FINDINGS}

It is not possible to select a definitive end point to the research, as the process, under an action research methodology, is ongoing. Consequently, the findings essentially take the form of a summary of what has been thus far achieved.

\section{Growers' Response}

The response rate for the questionnaire was $57.5 \%$. The findings indicate that growers had different reactions to the idea of employing electronic commerce. Of those who responded, $95 \%$ indicated they would like further information on the subject of electronic commerce. Growers across all age groups expressed interest.

\section{Growers' and Information Technology}

All of the growers participating in this investigation had access to a fax machine. Of the 22 growers who responded to the questionnaire, $72 \%$ owned or had access to a computer, and of those, $48 \%$ had modems. Of those growers so 
enabled, 33\% had a connection to the Internet. The findings show that growers are using a mixture of platforms. They used their computers for a variety of purposes, ranging from assisting with children's schoolwork to one respondent who wrote programs for a hobby. Only three respondents indicated that they used a computer for farm management tasks. None of the participants indicated that electronic commerce activities are currently undertaken, with the exclusion of the exchange of business information via a fax machine or telephone.

\section{Growers' Perception of Electronic Commerce}

At the commencement of this investigation a misconception existed amongst growers that electronic commerce, in the context of their undertakings, meant the ability to sell their stonefruit over the Internet. Only a few growers were aware of the broader nature and implications of electronic commerce, such as EDI and bar-coding.

\section{Status of Infrastructure}

The findings indicated a lack of supporting infrastructure. Wholesalers on the mainland do not use EDI or Email, nor do local transport companies. However, growers wishing to export may communicate with customs using standardised electronic forms, or with airlines via the Internet.

\section{Past Attempts at Cooperative Ventures}

The findings indicated that there have been a mixture of successes and failures regarding historic attempts to act cooperatively. For example, about 12 years ago, growers joined together in a cooperative venture to market their fruit. Unfortunately this was unsuccessful as many growers felt the distribution of profits was unfair. This has left some older growers wary of such proposals. The findings indicate that younger growers seem more inclined to enter joint operations.

Growers have had cooperative successes. One such incident involved the purchase of a large number of pine posts. Although the total amount purchased far exceeded the requirements of any individual grower, the bulk procurement enabled savings to be made by those involved.

Growers currently market their produce under a variety of brands. There is no single brand used. The Tasmanian Stonefruit Growers Association does offer generic packaging, but this is used by only a small number of growers. The findings also show that growers in general act as individuals, not as a unified group.

\section{Growers' Concerns}

Growers revealed concerns when informed of the manner in which information technology and electronic commerce could be employed. They include:

- Their limited technical knowledge;

- Their limited resources;

- Their need for immediate return on investment;

- Their preference for manual methods;

- Their cost of establishment; and,

- The difficulty in getting sufficient cooperation and commitment.

The concerns essentially fit into three categories: finance, knowledge and cooperation. Growers also expressed concern regarding the lack of a quality control. There is currently no universal methodology for addressing this issue in place. Growers are not concerned about the amount of inventory required to be kept, nor administrative costs. However, in the past goods have been lost in transit.

Growers reported a need for relevant and timely information. On the basis of the survey responses and personal conversations, it was ascertained that growers have the following three main information requirements:

- Weather;

- Rural news; and,

- New products. 


\section{DISCUSSION}

Beginning with an understanding of the technologies electronic commerce incorporates, it was possible to establish how these technologies could be applied and their suitability in particular circumstances. Not all of the benefits of electronic commerce being realised in the business world are available to the Tasmanian stonefruit growers. Not all of the current practices are applicable. Further, some factors would inhibit attempts to adopt electronic commerce practices.

The literature suggests that products such as stonefruit are not suited to direct Internet retailing. They are asset specific in that they need to be marketed within a short time of harvesting (Gregor et al. 1997). They fail to have adequacy of description, as growers consider that consumers like to see what they are buying. A further issue, raised by the growers, is the logistics involved in getting small quantities of perishable produce to geographically dispersed consumers. On this basis it would appear that direct sales to consumers are not viable. This does not preclude electronic commerce from being be used to support relationships between other entities in the industry, such as wholesalers or retailers (McCarthy et al. 1997). This may provide benefits by lowering inventory and administration costs (Mackay 1996). It is noted that inventory and administration are not of primary concern to growers at this point.

However, the literature suggests that the current lack of supporting technical infrastructure would pose an important hurdle, and that there would be initial cosis involved in establishing a suitable infrastructure if universal participation was desired. A further issue is that the other entities in a given industry must have the technology available to support any attempt at using electronic commerce technologies (Bloch et al. 1996). It is reasonable to extrapolate that some sort of critical mass is required.

This lack of infrastructure limits the short-term opportunities for stonefruit growers to employ electronic commerce (Bloch et al. 1997). Utilising the existing electronic communication's infrastructure, via telephones and fax machines, arguably constitutes a degree of participation in the world of electronic commerce (Schware \& Kimberley 1995b). As noted in a recent report from Monash University, some authors insist that communication involving computer applications is required (anon 1996). However, there is currently no support for EDI or bar-coding.

The very nature of the stonefruit industry also has an impact on the applicability of electronic commerce. As suggested earlier, the ability to facilitate disintermediation is one of the strengths of electronic commerce. However, the literature reveals strong arguments supporting the role of intermediaries in the marketing and distribution of agricultural products. These intermediaries provide value for the stonefruit growers in a variety of ways, such as bringing all of the produce and buyers together in one place, and taking the risk of payment from the customer away from the grower (McCarthy 1997). They also perform a pricing function (Matsuda 1996; 1997).

A further inhibitor to the adoption of electronic commerce arises from the stonefruit grower's historical attempts to change practices or act cooperatively. As noted earlier, past attempts at change have an intrinsic effect on future attempts. It was found that younger growers were more eager to adopt electronic commerce technologies. Older growers, many of whom have had experience with past attempts to change, expressed more concern.

\section{POTENTIAL APPLICATIONS OF ELECTRONIC COMMERCE}

Although the literature suggests that stonefruit is unsuited for sales directly to consumers via the Internet, the Internet can provide a medium for relatively inexpensive mass and niche marketing, and for providing product information. It can also be a useful means for receiving customer feedback to facilitate improvement, an important part of marketing (McCarthy et al. 1997).

The literature indicates that growers who do sell to export markets are often contacted by overseas agents to see if they can supply. Luostarinen and Welch (1993) report that many initial outward operations are the result of foreign inquiry or unsolicited orders; hence an Internet presence could provide benefits by increasing the awareness of Tasmania's stonefruit grower's capabilities. The Internet is also a useful means for communicating with those associates and trading partners who have an online connection (Kalakota \& Whinston 1996). These entities could include other growers, customs and airlines for example. Another possible use is for gathering information (Kalakota $\&$ Whinston 1996). The Internet provides a means to satisfy the grower's stated information requirements.

An electronic commerce framework can also incorporate quality control. There are currently no universal quality control processes in place within the stonefruit industry. The findings indicate that growers are aware of the 
importance of quality control, and are keen to remedy the situation. Information technology can assist primary producers in this matter as shown by Schware and Kimberley (1995b).

The use of EDI and/or bar-coding, if judged viable, could assist in overcoming the problem of goods going missing in transit. Hill (1997) notes that this is a concern for many organisations. The findings suggest this is not a major issue for growers, but the transfer of the title of ownership of goods in transit is a grey area that could be addressed, and the solution supported by electronic commerce technologies (Hill 1997). Some technologies such as EDI are not currently supported, and are regarded as price prohibitive in consideration of the low volume of fruit and administration. However other technologies, such as the Internet are available and accessible.

Should growers elect to employ electronic commerce technologies, it is suggested that an incremental approach be adopted. Growers could begin their electronic commerce efforts by establishing web sites that provide product information. A decision would be required as to whether one web site for all Tasmanian stonefruit growers is desired, or if growers should pursue their own line of marketing. The literature suggests a cooperative undertaking would provide the most benefit, and be least confusing to trading partners. As part of the incremental process, growers could also begin to use Email where possible. They could communicate with each other, and with other entities (McCarthy et al. 1997). The next step could be the adoption of EDI, if it is deemed viable and necessary. By approaching electronic commerce in this incremental manner, growers can overcome some of their concerns as their knowledge and experience increases (Blanchard 1997).

Due to the variety of hardware and software platforms being used, there may be a role for an information or electronic broker. This entity could, amongst other things, provide technical assistance, establish and maintain a web site, and act as a central body for the distribution of information (Rugge \& Glossbrenner 1995). Thus growers could participate regardless of their individual technical and financial resource status.

It is evident that there are significant possibilities for electronic commerce applications within the environment under study, and there are also given inhibiting elements. The current practices within the industry function to the general satisfaction of the growers. However it is accepted that change is both inevitable and necessary, and the specific nature of the change may be influenced or even dictated by parties other than the growers themselves. It appears that through interaction and participation growers are developing an understanding of the issues the research has raised. Growers realise that there is a need for awareness of the potential of electronic commerce, and that this awareness must precede any implementation.

\section{Concurrence with Other Studies}

The researcher could find no other investigations that considered the potential for the use of electronic commerce in primary industry endeavours involving SMEs. However, by characterising stonefruit growers as SMEs, it is possible to find some, more general, concurrence. Lawrence (1996) found that SMEs had similar concerns regarding the adoption of electronic commerce. These findings were in turn supported by Cameron and Clarke (1996) and Lee and Clarke (1996).

The general misconception within the Tasmanian stonefruit industry regarding the possible application of electronic commerce is supported by findings from Monash University. The report states that "EDI, one of the subset technologies of electronic commerce, is often confused by SMEs as being EC" (Anon 1996:13).

The research findings regarding a lack of infrastructure to support electronic commerce implementation within the stonefruit industry are also reflected by the Monash University report. The report states that one of the six key issues deterring SMEs from adopting electronic commerce is that there is "...no 'critical mass' of electronic commerce and communications partners" Anon (1996:17).

\section{Further Research}

The findings provide a basis for further investigation. For example, the fact that stonefruit is not a good product to sell directly over the Internet has implications for managing risk. Forward selling is one way of managing the risk of price uncertainty ${ }^{8}$. Further research could investigate the role electronic commerce can play in risk management. The

8 Kilpatrick, S., (23/09/97) Personal Conversation, Associate Director, Centre for Research and Learning in Regional Australia, Newham Campus, University of Tasmania. 
research could also provide a platform for further investigations into change management in SMEs. It is noted that there is a lack of information available on this matter. Research into the manner in which SMEs information requirements evolve with the adoption of electronic commerce could also provide interesting insights.

The important role that agricultural industries play in the Australian economy proclaims the need to support these industries in their efforts to adopt new technologies and remain globally competitive. In this context, research can play an important role in both identifying and raising awareness of the issues, opportunities and benefits of electronic commerce to primary producers. This research may provide a useful starting point and framework for the substantial work that remains to be done. Further, it indicates potential areas of interest or concern to those involved in similar industries.

\section{REFERENCES}

Achterberg, J., (1991) Information Systems Research in the Postmodern Period, pp281-294, in Nissen H, Klein H, Hirscheim R, Information Systems Research: Contemporary Approaches and Emergent Traditions, Elsevier Science Publishers, North Holland.

Anon., (1996) Advice on Electronic Commerce Programs for Small to Medium Sized Enterprises (SMEs), Prepared for the Department of Industry Science and Tourism, Centre for Electronic Commerce, Monash University.

Bloch, M., Pigneur, Y., Segev, A., (1996) Leveraging Electronic Commerce for Competitive Advantage: A Business Value Framework, Ninth International Conference on EDI-IOS, Bled., Slovenia.

Burnes, B., (1996) Managing Change: A Strategic Approach to Organisation Dynamics. Pitman Publishing, London.

Cameron, J., Clarke, R., (1996) Towards A theoretical Framework For Collaborative Electronic Commerce Projects Involving Small And Medium Sized Enterprises, Ninth International Conference on EDI-IOS, Bled,. Slovenia.

Dawson, P., (1994) Organisational Change, A Processual Approach, Paul Chapman Publishing, London.

Gregor, S., Newman, S., Larner, T., (1997) The Australian Meat Industry, the Electronic Market Hypothesis and Internet Marketing, Tenth International Conference on EDI-IOS, Bled,. Slovenia.

Golden, W., (1996) Electronic Commerce at Work: Kennys Bookshop \& Art Galleries, Galaway, Ireland, Ninth International Conference on EDI-IOS, Bled., Slovenia.

Hill, C., (1997) International Business: Competing In The Global Marketplace, $2^{\text {nd }}$ Ed., Irwin Books., U.S.A.

Kalakota, R., Whinston, A., (1996) Frontiers of Electronic Commerce, Addison Wesley, New York.

Kinsey, J., (1994) Changes in Food Consumption From Mass Marketing To Niché Market, in Matsuda, T., (1997) Agricultural Wholesale Markets In An Electronic Commerce Environment, Reprinted From The Technical Bulletin Of The Faculty Of Horticulture, Chiba University, No. 51.

Lawrence, K., (1996) Electronic Commerce \& SMEs, University of Tasmania, Honours Thesis

Lee, H., Clark, R., (1996) Economic Benefits and Adoption Barriers of Electronic Market Systems, Ninth International Conference on EDI-IOS, Bled., Slovenia.

Luostarinen, R. and Welch, L., (1993) International Business Operations, Kyiiri Oy, Helsinki.

Mackay D., (1996) EDI and the Australian Automotive Industry, in Fischer, in Fischer, L., Electronic Commerce, Profiting from Business On-Line, Future Strategies Inc. Book Division, Florida.

Matsuda, T. 1994, The Use Of Information Technology To Achieve Accurate Pricing In Agricultural Commodity Markets In Japan, Information Technology and People, MCB University Press, Vol. 7 No. 3 , pp 37-49.

Matsuda, T., (1996) Electronic Commerce and Electronic Markets for Agriculture, Ninth International Conference on EDI-IOS, Bled., Slovenia.

Matsuda, T., (1997) Agricultural Wholesale Markets In An Electronic Commerce Environment, Reprinted From The Technical Bulletin Of The Faculty Of Horticulture, Chiba University, No. 51

Matsuda, T., Clark, T. and Lee, H., (1997) Electronic Commerce for Agricultural Transactions: Role of Intermediaries and Accurate Pricing, In J.F. Nunamaker and R. H. Sprauge (eds.). proceedings of the Thirteenth Annual Hawaii International Conference on Systems Science, Vol IV, 13-30.

McCarthy, E., Perreault, W. and Quester, P., (1997) Basic marketing, A Managerial Approach, Irwin Publishing, London.

Minichiello, V., Aroni, R., Timewell, E., Alexander, L., (1995) Indepth Interviewing, $2^{\text {nd }}$ Ed., Longman Australia. 
Neuman W L., (1994) Social Research Methods: Qualitative and Quantitative Approaches, $2^{\text {nd }}$ Edition, Allyn and Bacon, Sydney.

Noe, R., Hollenbeck, J., Gerhart, B., Wright, P. (1997) Human Resource Management: Gaining A Competitive Advantage, $2^{\text {nd }}$ Ed., Irwin Books, Burr Ridge.

Plunkett, S., (1997) "E' Is For Extracting the Internet-Commerce Digit", Business Review Weekly, Vol. 19, No. 35.

Porter, M., (1990) The Competitive Advantage of Nations, The Free Press, New York.

Robbins, S., and Barnwell, N., (1994) Organisational Theory in Australia. $2^{\text {nd }}$ Ed., Prentice Hall, Sydney.

Row, H., (1996) The Electric Handshake, Datamation, October.

Rugge, S., Glossbrenner, A., (1995) The Information Brokers Handbook, $2^{\text {nd }}$ Ed. McGraw Hill, New York.

Schermerhorn, J., Hunt, J., Osborn, R., (1988) Managing Organisational Behaviour, $3^{\text {rd }}$ Ed., John Wiley and Sons, New York.

Schware, R. and Kimberley, P., (1995a) Information Technology and National Trade Facilitation: Making The Most Of Global Trade. The World Bank, Technical Paper No. 316.

Schware, R. and Kimberley, P., (1995b) Information Technology and National Trade Facilitation: Guide To Best Practice. The World Bank, Technical Paper No. 317.

Strauss, A., (1987) Qualitative Analysis For Social Scientists, Cambridge University Press. England.

Wyte, W., (1991) Participatory Action Research, Sage Publications, California.

\section{ACKNOWLEDGEMENTS}

The author would like to extend unreserved gratitude to the Tasmanian Stonefruit growers for their participation in this investigation. Thanks also the academic staff and post-graduates from the School of Information Systems, University of Tasmania, for their invaluable input. 